\title{
Evaluation of Risk Behavior in Gambling Addicted and Opioid Addicted Individuals
}

\section{Edward J. Gorzelańczyk ${ }^{1,2,3,4 *}$, Piotr Walecki ${ }^{5 *}$, Monika Błaszczyszyn ${ }^{6}$, Ewa Laskowska ${ }^{7}$ and Aleksandra Kawala-Sterniuk ${ }^{8 *}$}

\begin{abstract}
${ }^{1}$ Department of Theoretical Basis of Bio-Medical Sciences and Medical Informatics, Nicolaus Copernicus University Collegium Medicum, Bydgoszcz, Poland, ${ }^{2}$ Institute of Philosophy, Kazimierz Wielki University, Bydgoszcz, Poland, ${ }^{3}$ Babinski Specialist Psychiatric Healthcare Center, Outpatient Addiction Treatment, Lodz, Poland, ${ }^{4}$ The Society for the Substitution Treatment of Addiction "Medically Assisted Recovery", Bydgoszcz, Poland, ${ }^{5}$ Department of Bioinformatics and Telemedicine, Jagiellonian University - Collegium Medicum, Krakow, Poland, ${ }^{6}$ Faculty of Physical Education and Physiotherapy, Opole University of Technology, Opole, Poland, ${ }^{7}$ Faculty of Medicine, Nicolaus Copernicus University - Collegium Medicum, Bydgoszcz, Poland, ${ }^{8}$ Faculty of Electrical Engineering, Automatic Control and Informatics, Opole University of Technology, Opole, Poland
\end{abstract}

OPEN ACCESS

Evidence suggests that both opioid addicted and gambling addicted individuals are characterized by higher levels of risky behavior in comparison to healthy people. It has been shown that the administration of substitution drugs can reduce cravings for opioids and the risky decisions made by individuals addicted to opioids. Although it is suggested that the neurobiological foundations of addiction are similar, it is possible that risk behaviors in opioid addicts may differ in detail from those addicted to gambling. The aim of this work was to compare the level of risk behavior in individuals addicted to opioid, with that of individuals addicted to gambling, using the lowa Gambling Task (IGT). The score and response time during the task were measured. It was also observed, in the basis of the whole IGT test, that individuals addicted to gambling make riskier decisions in comparison to healthy individuals from the control group but less riskier decisions in comparison to individuals addicted to opioids, before administration of methadone and without any statistically significant difference after administration of methadone-as there has been growing evidence that methadone administration is strongly associated with a significant decrease in risky behavior.

Keywords: addiction, methadone therapy, gambling, opioids, lowa gamble task, cortico-subcortical loops, philosophy of mind

\section{INTRODUCTION}

The evidence, collected by inter alia authors of this paper, suggests that both opioid addicted and gambling addicted individuals can be characterized with higher levels of risk behavior in comparison to healthy people (Brevers et al., 2013; Gorzelańczyk et al., 2014). It has been shown that the administration of substitution drugs can reduce cravings for opioids and also decrease risky decision making among individuals addicted to opioids (Gorzelańczyk et al., 2014; Hu et al., 2019; Kriegler et al., 2019; Kelty et al., 2020). Although it is suggested that the neurobiological basis of addiction is similar, it is possible to assume that the risk behavior in individuals addicted to opioids can differ from gambling addicted individuals (Zeng et al., 2016; Chen et al., 2017; Coppola et al., 2017; Majuri et al., 2017; Schwaninger et al., 2017; Victorri-Vigneau et al., 2018; Kim et al., 2019). 
Therefore, the main aim of this study was to compare the level and dynamics of risk behavior in opioid addicts with those addicted to gambling while performing the Iowa Gambling Task (IGT). The score and response time were measured during the IGT performance. The authors introduced for the first time the response time measurement in the IGT test as a new parameter. Response time is assessed for correct and incorrect choices and can be useful in the differential diagnosis of addicts Gorzelańczyk et al. (2014).

A large number of similarities between drug addiction and gambling addiction were found recently. It was noticed that those addictions share some common mechanism (American Psychiatric Association, 2013; Brevers et al., 2013). Addicted individuals are more prone to show risky behavior in comparison to healthy people (Leeman and Potenza, 2012; Ahmadi et al., 2017; Chamberlain and Grant, 2019).

It was also observed that impairments in decision-making reflect drifts into risky behaviors and may be at first manifested with some psychiatric symptoms or cognitive dysfunctions (Chamberlain and Grant, 2019; Vegni et al., 2019). Misuse and addiction to opioids have become a major civil challenge in the world (Volkow et al., 2018).

Gambling is an activity, where something valuable is risked on behalf of a chance for winning something even more valuable (Yau and Potenza, 2015). The chances are however less than certain (Nautiyal et al., 2017). At first it may seem like a recreational activity, as between 50 and $80 \%$ of the general population gamble at least once a year. Individuals who are addicted to gambling tend to increase their risky behavior, which can result in serious financial problems (Leeman and Potenza, 2012; Brevers et al., 2013).

From the neuropsychiatric and neurobiological perspectives, risky behavior is connected to malfunctioning of mesolimbic and executive control circuits (American Psychiatric Association, 2013; Engel and Caceda, 2015). It is known that the use of psychoactive substances can change structures and functions of circuits involved in risk decision making (Gilman et al., 2015). The structural and functional changes of the elements of the cortico-subcortical loops have been observed among addicted people (Gorzelańczyk et al., 2014, 2016; Tarnowska et al., 2018).

It has also been observed that poker gamblers exhibited higher ventral-striatal but lower dorsolateral prefrontal and orbitofrontal activation during Iowa Gambling Task performance as well as higher ventral-striatal connectivity and connectivity in posterior cingulate cortex, occipital gyrus, and temporal gyrus (Leeman and Potenza, 2012). In addition, the severity of gambling is associated with the activation of ventral striatum, occipital fusiform gyrus and middle temporal gyrus (Brevers et al., 2016). The data from experiments on pathological gamblers show increased activation in response to visual gambling cues in such brain structures as the right dorsolateral prefrontal cortex, the right parahippocampal gyrus, and the left occipital cortex (Leeman and Potenza, 2012; Epstein and Silbersweig, 2016; Chamberlain and Grant, 2019).

In this paper the authors compared various IGT parameters of risky behaviors between addicted (to gambling or opioids) and healthy individuals using the most popular Iowa Gambling Task, which is still regarded as the classical measurement tool for decision making in this clinical population (Brevers et al., 2013). The IGT test is used to assess risky behavior also in addicted individuals (Ahn et al., 2016b; Mallorquí-Bagué et al., 2016; Kovács et al., 2017; Brière et al., 2019; Khoury et al., 2019; Lin et al., 2019; Trotzke et al., 2019).

\subsection{IOWA Gambling Task}

The Iowa Gambling Task (IGT) is a psychological test with a continuous task performed on a computer, which simulates various situations for decisions making (Bechara et al., 1994).

Disease categories associated with risky behaviors include inter alia: compulsive stealing (kleptomania), compulsive shopping, and compulsive sexual behavior as well as addictions to opioids and other chemical substances (Chamberlain and Grant, 2019).

The Iowa Gambling Task (IGT) is the most popular test for assessment of an appropriate decision-making process (Bechara et al., 1994; Tanabe et al., 2007; Brevers et al., 2013). It deals with uncertainty in a context of penalty and reward, with some choices being advantageous in the short-term (high reward), but disadvantageous in the long run (higher penalty), there are also other choices, which are less attractive in the shortterm (low reward), but advantageous in the long run (lower penalty) (Brevers et al., 2013; Vasconcelos et al., 2015; Smith et al., 2016). It shows preferences of the tested participants for choosing short-term gains at the risk of larger loses (Tanabe et al., 2007). The choice between long- and short-term benefits enables distinction between gambling and opioid addicts and description of particular decision-making mechanisms. Also, IGT can be a very good measure of impaired decision-making in people suffering various psychiatric or neurological conditions (Bechara et al., 1994; Upton et al., 2012; Brevers et al., 2013). The IGT is the most popular decision-making task applied in numerous clinical studies (Upton et al., 2012; Ahn et al., 2016a).

\subsection{Background to the Study}

Studies on decision making in addicted participants have a very long history and have resulted in the common knowledge that substance addicted individuals (SDI) usually prefer choices bringing immediate benefits, even if there are negative consequences, such as inter alia loss of job, home or family. For such study purposes the IGT simulating real life decision making is frequently carried out. It is also the most popular decision-making task that has been applied in numerous clinical studies (as it was mentioned above) (Upton et al., 2012).

Based on a thorough literature background-both drug addicts and healthy study participants tend to choose decks with net losses at the beginning of the test, but only the healthy individuals are able to shift their choices to the decks with net gains, learning from their experience, while the addicted individual fail to do so (Bechara and Damasio, 2002; Bechara et al., 2002; Upton et al., 2012).

\section{METHODS}

For the study purposes 132 subjects $(\boldsymbol{n}=\mathbf{1 3 2})$ were recruited for this study from opioid substitution clinics in various towns 
in Poland (Bydgoszcz, Gdańsk, Kraków). Summary of studyparticipants was illustrated with Figure 1.

The participants were recruited among clinics' patients, prisoners, and healthy people. The participants were diagnosed in accordance with the ICD - 10 criteria.

The participants' selection criteria included:

- Meeting the diagnostic and statistical manual criteria of opioid dependence;
- Age range 21-60 years old;

- Absence of illicit drugs or alcohol withdrawal or intoxication at time of the study visits;

- Absence of history of psychotic mental illnesses or history of traumatic brain injuries;

- Absence of history of cognitive or memory problems;

- Subjects are stable on methadone maintenance for at least 2 weeks.

\begin{tabular}{|c|c|c|c|c|}
\hline GROUPS & $n$ - number & AGE & SEX (male : female) & PLACE OF TESTING \\
\hline $\begin{array}{l}\text { GAMBLING } \\
89\end{array}$ & $n=33$ & $35.23 \pm 8.76$ & 21:12 & 1 \\
\hline $\begin{array}{l}\text { OPIOID_0 } \\
082\end{array}$ & $n=30$ & $33.52 \pm 10.53$ & $17: 13$ & 2 \\
\hline $\begin{array}{l}\text { OPIOID_1 } \\
908\end{array}$ & $n=30$ & $32.94 \pm 9.73$ & $18: 12$ & 2 \\
\hline CONTROL & $n=39$ & $28.63 \pm 12.53$ & $17: 22$ & $1,3,4$ \\
\hline
\end{tabular}

GROUPS:

GAMBLING - gambling addicted individuals

OPIOID_0 - opioid addicts before methadone administration

OPIOID_1 - opioid addicts after methadone administration

CONTROL - healthy individuals

n - number of randomly selected participants

AGE - mean \pm standard deviation

PLACE OF TESTING:

1. Bydgoszcz-Fordon Prison in Bydgoszcz, Poland

2. NZOZ "Medseven" - Addiction Treatment Clinic, Bydgoszcz and Gdańsk

3. Ludwik Rydygier Collegium Medicum in Bydgoszcz, Nicolaus Copernicus University in Toruń

4. Jagiellonian University Medical College, Kraków 
The recruitment of gambling addicts was carried out mainly in prisons. The male/female ratio among gambling addicts is higher among males, as female prisoners constitute only $4.4 \%$ of all prisoners in Poland (2020). Gender gambling addiction research requires additional logistical efforts due to the significant disproportion in the frequency of this disorder between males and females. One-sex comparative studies are advisable.

The Mini-Mental State Examination (MMSE) was used as a screening device for cognitive impairment. The individuals with a minimum of 27 points in MMSE were included in the study. The educational structure of the particular group is presented in Table 1.

The gambling addicts were included in the study after a psychiatric interview examination. Nicotine addiction did not exclude individuals from the study. Individuals with comorbid psychiatric disorders other than gambling were however excluded.

The dose of this substitution was selected individually in order to prevent the occurrence of withdrawal symptoms. The average dose of methadone in the study group was $70 \mathrm{mg}$ per day, administered orally in a single dose.

The limitation concerning the level of education of the study participants results from sources of acquired material. However, the behavioral strategy in performing the IGT test is quite specific for gambling addicts. Further research is necessary in terms of gender and education.

All participants (opioids addict, gambling addicts, healthy individuals) had to provide written informed consent in order to take part in this study. To conduct the study, the consent of the Bioethics Commission at Medical College in Bydgoszcz, Nicolaus Copernicus University in Torun, Poland was obtained (Consent no. $K B / 416 / 2008)$.

After being appropriately classified for the projectparticipation-each subject was scheduled for the IGT session testing. The opioid addicted individuals were divided into two groups. Individuals from the first group were tested before the methadone administration and individuals from the second group performed the IGT test about one and a half hours after the methadone administration.

After consenting to participate in the study, each subject was scheduled for the sessions of IGT testing. The IGT is a psychological task thought to simulate real-life decision making (Bechara et al., 1994). The authors of this work used the IGT, which is a part of the PEBL Test Battery (Mueller and Piper, 2014).

The construction of the IGT test consists of simulation games and gambling. In the task there are four decks of cards which contain the winner's and loser's cards. The winner's and

TABLE 1 | Structure of education among investigated individuals.

\begin{tabular}{lcccc}
\hline & Gambling & Opioid_0 & Opioid_1 & Control \\
\hline Level of education & $n=33$ & $n=30$ & $n=30$ & $n=39$ \\
Primary & 18 & 20 & 19 & 17 \\
Secondary & 10 & 8 & 8 & 15 \\
Tertiary & 5 & 2 & 3 & 7
\end{tabular}

loser's cards contain different monetary values. It means that for each deck of cards a certain amount of reward and penalty is attributed. An individual has to choose a deck containing the cards of the highest profit (Bechara et al., 1994; Fineberg et al., 2010). There are the four decks of cards marked as $A, B, C$, and $D$. The first two decks ( $A$ and $B$ ) are disadvantageous since, although immediate gains are large, the gain is followed by large losses at unpredictable intervals. In contrast, the other two decks ( $C$ and D) are advantageous.

In this case the immediate gains are smaller but there are also unpredictable losses, which are also small so that in the longer term the player gains more.

During the IGT test performance, the study subjects sit in front of a computer screen. The study is carried out in a way that, while using the computer's mouse, the study participant clicks on a card from any of the four decks. A standard administration of 100 trials (i.e., selection of 100 cards) was done once in individuals from all groups (opioid addicted, behaviorally addicted and healthy individuals). In this study the response time was given in milliseconds (ms) and for every subject was recorded in every trial. The response time is defined as time from the appearance of the cards on the screen till the time of card selection (by clicking a computer mouse button). The main dependent measure used for the calculation of the IGT performance was the net score. It was calculated by subtracting the number of cards selected from the disadvantageous decks from the numbers of cards selected from the advantageous decks $(C+D)-(A+B)$. Lower scores reflected a more disadvantageous than advantageous decision-making performance.

In Figure 2, a general scheme of the conducted experiment is presented. Individuals from each group were tested once. This procedure excludes the learning effect Pasion et al. (2017); Almy et al. (2018).

\section{RESULTS}

In this work the number of risky decisions (decks $\mathrm{A}+\mathrm{B}$ ) and safe decisions (decks $\mathrm{C}+\mathrm{D}$ ) was compared in opioid addicts (before and after methadone administration) with those addicted to gambling and with the healthy individuals.

It was found (One-way ANOVA. $F=4.529, p=0.00472$ ) that the participants from the control group $34.85 \pm 11.52$ take less risky decisions compared to the gambling addicts $41.85 \pm$ 11.05 (mean and standard deviation) and to the opioid addicted individuals (before the administration of methadone) $46.07 \pm$ 15.09 and to the opioid addicted individuals after the methadone administration $42 \pm 14.46$.

It was also found (One-way ANOVA $F=6.666, p=$ $0.00032)$ that the gambling addicted individuals are less likely to make safe decisions $(58.152 \pm 11.0542)$ compared to the subjects from the control group $(65.359 \pm 11.5656)$, but take less safe decisions compared to the opioid addicted individuals prior the methadone administration (51.767 \pm 14.0263$)$ and that there is no significant statistical difference compared to the opioid addicted individuals after the methadone administration (57.6 \pm 14.2577). In Table 2 (for Risky Decisions) and Table 3 


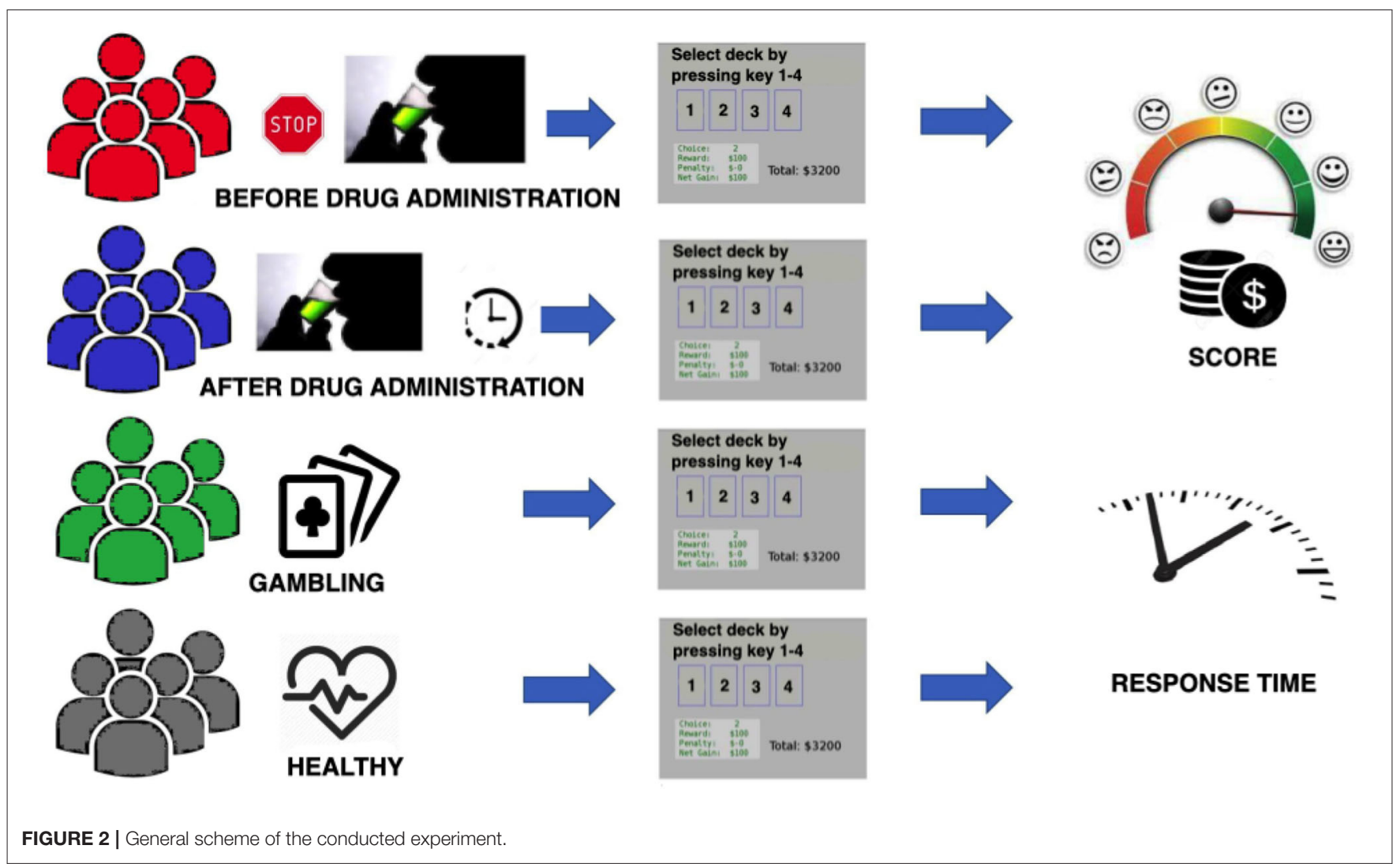

TABLE 2 | Values for probabilities after post-hoc tests-risky decisions.

Turkey HSD test; variable risky decisions.

Approximate probabilities for post-hoc tests;

Error: between $M S=168.84, d f=128.00$

\begin{tabular}{lccccc} 
& & $\mathbf{( 1 )}$ & $\mathbf{( 2 )}$ & $\mathbf{( 3 )}$ & $\mathbf{( 4 )}$ \\
\cline { 2 - 6 } Cell no. & Groups & $\mathbf{4 1 . 8 4 8}$ & $\mathbf{3 4 . 8 4 6}$ & $\mathbf{4 6 . 0 6 7}$ & $\mathbf{4 2 . 0 0 0}$ \\
\hline 1 & Gambling & & $\mathbf{0 . 0 4 6 4 6 5}$ & 0.457858 & 0.999948 \\
2 & Control & $\mathbf{0 . 0 4 6 4 6 5}$ & & $\mathbf{0 . 0 0 0 3 0 0}$ & $\mathbf{0 . 0 4 8 0 9 4}$ \\
3 & Opioid_0 & 0.457858 & $\mathbf{0 . 0 0 0 3 0 0}$ & & 0.511049 \\
4 & Opioid_1 & 0.999948 & $\mathbf{0 . 0 4 8 0 9 4}$ & 0.511049 & \\
\hline
\end{tabular}

Bold values are significantly important statistical values $(p<0.05)$.

(for Safe Decisions) the obtained results using Turkey HSD test are presented.

It was found (ANOVA $F=14.164, p=0.00000$ ) that the average response time (milliseconds) of gambling addicts (1516.748 \pm 930.15) was statistically significantly longer than the mean response time of the individuals from the control group $(646.6121 \pm 284.23)$ and had a similar mean response time without a significant statistical difference when compared to the opioid addicted individuals prior to methadone administration (1418.943 \pm 823.46$)$ and the opioid addicts after the administration of methadone $(1654.676 \pm 757.99)$.

It was also found that the mean response time of the individuals from the control group after reward $636.641 \pm$
TABLE 3 | Values for probabilities after post-hoc tests-safe decisions.

Tukey HSD test; Variable Safe Decisions.

Approximate Probabilities for post-hoc Tests;

Error: Between MS $=160.89, d f=128.00$

\begin{tabular}{lccccc} 
& & $\mathbf{( 1 )}$ & $\mathbf{( 2 )}$ & $\mathbf{( 3 )}$ & $\mathbf{( 4 )}$ \\
\cline { 2 - 6 } Cell no. & Groups & $\mathbf{5 8 . 1 5 2}$ & $\mathbf{6 5 . 1 5 4}$ & $\mathbf{5 1 . 7 6 7}$ & $\mathbf{5 7 . 6 0 0}$ \\
\hline 1 & Gambling & & $\mathbf{0 . 0 4 9 1 6 8}$ & 0.140795 & 0.997764 \\
2 & Control & $\mathbf{0 . 0 4 9 1 6 8}$ & & $\mathbf{0 . 0 0 0 0 2 0}$ & $\mathbf{0 . 0 3 4 9 5 8}$ \\
3 & Opioid_0 & 0.140795 & $\mathbf{0 . 0 0 0 0 2 0}$ & & 0.223987 \\
4 & Opioid_1 & 0.997764 & $\mathbf{0 . 0 3 4 9 5 8}$ & 0.223987 &
\end{tabular}

Bold values are significantly important statistical values $(p<0.05)$.

273.872 and after penalty $682.8462 \pm 351.07$ (Wilks lambda $F=8.856, p=0.000)$ is statistically significantly shorter than the mean response time of gambling addicts after reward $(1580.636 \pm 965.5572)$ and penalty $(1296.030 \pm 910.7465)$, opioid addicts before the methadone administration (reward $1680.567 \pm$ 840.7316 ; penalty $1530.933 \pm 845.7030)$ and opioid addicts after taking methadone (reward $1432.9 \pm 760.0489$; penalty $1357.167 \pm 794.7040)$.

In Table 4, the response time (expressed in [ms]) after reward, as a result of post-hoc tests is presented, while Table 5 presents the response time after penalty.

Figure 3 illustrates the percentage of made risky decisions. Figure 4 shows comparison of all groups in regards of time after reward and after penalty. 
Table 6 presents values for the response time-mean of the entire test.

\section{DISCUSSION}

Various cognitive models have been applied and developed for the past 20 years in order to understand decision making deficits in drug-addicted, brain-damaged individuals (Ahn et al., 2016a).

TABLE 4 | Values for the response time (in [ms]) after post-hoc tests-after reward.

Tukey HSD test; Variable response time [ms] after reward.

Approximate probabilities for post-hoc tests;

Error: between MS $=5464 E 2, d f=128.00$

\begin{tabular}{lccccc} 
& & $\mathbf{( 1 )}$ & $\mathbf{( 2 )}$ & $\mathbf{( 3 )}$ & $\mathbf{( 4 )}$ \\
\cline { 2 - 6 } Cell no. & Groups & $\mathbf{1 5 8 0 . 6}$ & $\mathbf{6 3 6 . 6 4}$ & $\mathbf{1 6 8 0 . 6}$ & $\mathbf{1 4 3 2 . 9}$ \\
\hline 1 & Gambling & & $\mathbf{0 . 0 0 0 0 0 8}$ & 0.950305 & 0.857985 \\
2 & Control & $\mathbf{0 . 0 0 0 0 0 8}$ & & $\mathbf{0 . 0 0 0 0 0 8}$ & $\mathbf{0 . 0 0 0 0 6 0}$ \\
3 & Opioid_0 & 0.950305 & $\mathbf{0 . 0 0 0 0 0 8}$ & & 0.564378 \\
4 & Opioid_1 & 0.857985 & $\mathbf{0 . 0 0 0 0 6 0}$ & 0.564378 &
\end{tabular}

Bold values are significantly important statistical values $(p<0.05)$.
Decision making triggers simultaneous motor, emotional, and cognitive functions (Dixon et al., 2017; Weinstein et al., 2017; Hilber et al., 2019). Therefore, the authors of this work are looking for answers on to what extent behavioral and chemical addictions have common features and to what extent they differ from each other. The results of many studies indicate that alcohol, cocaine, heroin, cannabinoids, nicotine, and glucose as well as gambling increase risky behavior and cause activation
TABLE 5 | Values for the response time (in [ms]) after post-hoc tests-after penalty.

Tukey HSD test; variable response time [ms] after penalty.

Approximate probabilities for post-hoc tests;

Error: between MS = 5491E2, $d f=128.00$

\begin{tabular}{lccccc} 
& & $(\mathbf{1})$ & $\mathbf{( 2 )}$ & $\mathbf{( 3 )}$ & $\mathbf{( 4 )}$ \\
Cell no. & Groups & $\mathbf{1 2 9 6 . 0}$ & $\mathbf{6 8 2 . 8 5}$ & $\mathbf{1 5 3 0 . 9}$ & $\mathbf{1 3 5 7 . 2}$ \\
\hline 1 & Gambling & & $\mathbf{0 . 0 0 2 6 4 7}$ & 0.590658 & 0.987930 \\
2 & Control & $\mathbf{0 . 0 0 2 6 4 7}$ & & $\mathbf{0 . 0 0 0 0 2 1}$ & $\mathbf{0 . 0 0 1 0 4 4}$ \\
3 & Opioid_0 & 0.590658 & $\mathbf{0 . 0 0 0 0 2 1}$ & & 0.800470 \\
4 & Opioid_1 & 0.987930 & $\mathbf{0 . 0 0 1 0 4 4}$ & 0.800470 & \\
\hline
\end{tabular}

Bold values are significantly important statistical values $(p<0.05)$.

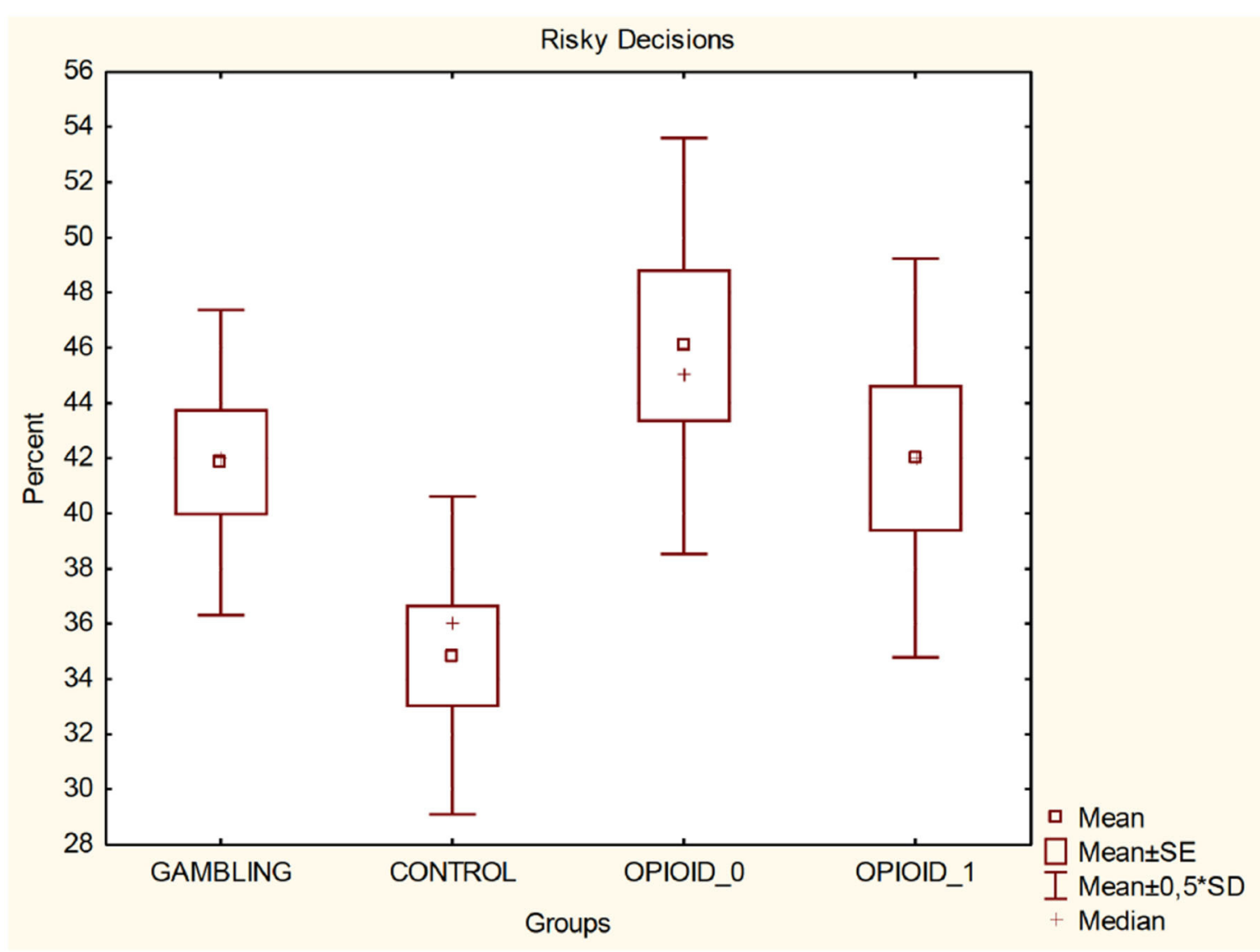

FIGURE 3 | Risky decisions-percentage. 


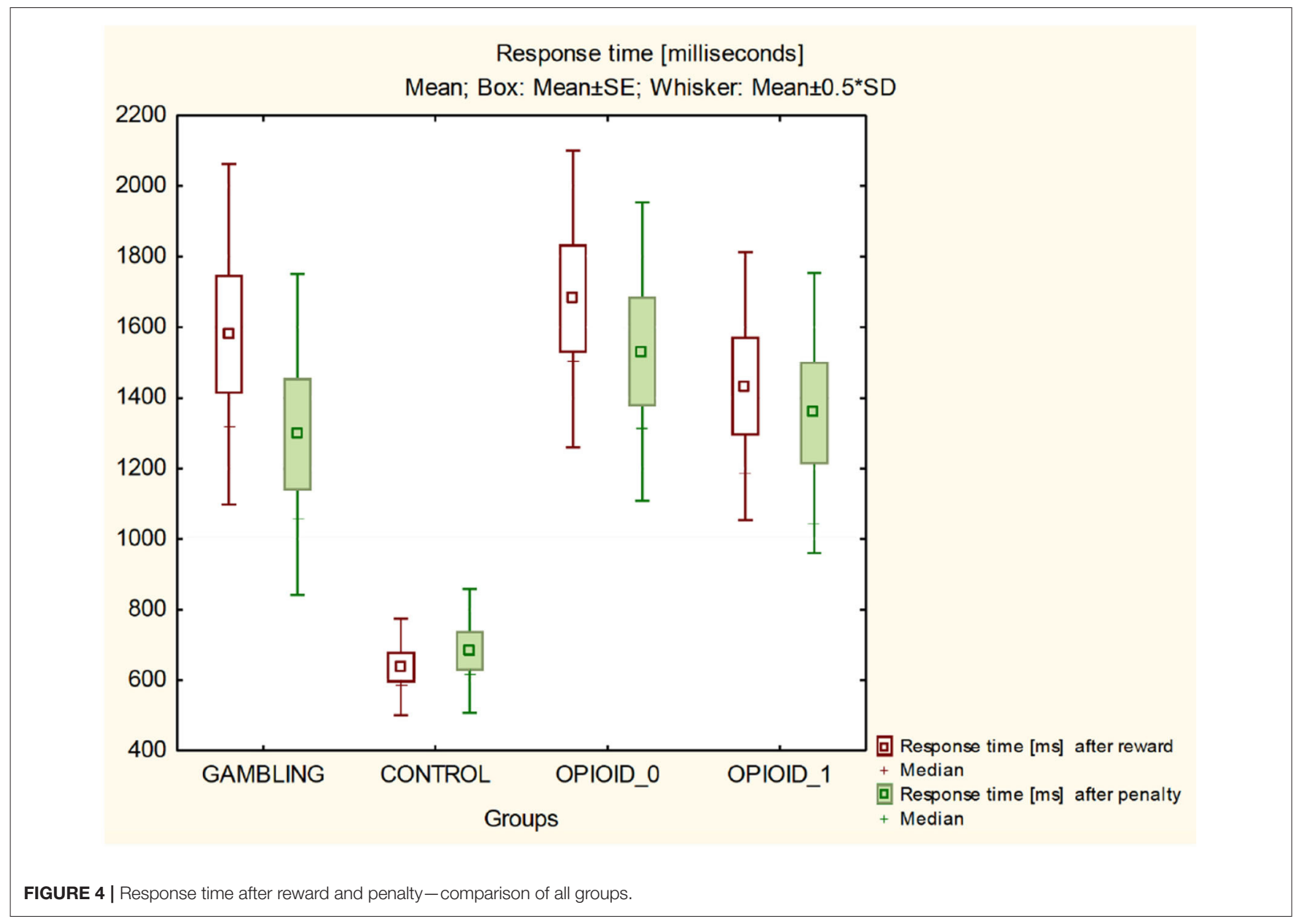

TABLE 6 | Values for the response time [ms] mean of the entire test.

Tukey HSD test; variable response time [ms] after penalty.

Approximate probabilities for post-hoc tests;

Error: between MS $=5241 E 2, d f=128.00$

\begin{tabular}{lccccc} 
& & $(\mathbf{1})$ & $\mathbf{( 2 )}$ & $\mathbf{( 3 )}$ & $\mathbf{( 4 )}$ \\
\cline { 2 - 6 } Cell no. & Groups & $\mathbf{1 5 1 6 . 7}$ & $\mathbf{6 4 6 . 6 1}$ & $\mathbf{1 6 5 4 . 7}$ & $\mathbf{1 4 1 8 . 9}$ \\
\hline 1 & Gambling & & $\mathbf{0 . 0 0 0 0 1 0}$ & 0.874445 & 0.950398 \\
2 & Control & $\mathbf{0 . 0 0 0 0 1 0}$ & & $\mathbf{0 . 0 0 0 0 0 8}$ & $\mathbf{0 . 0 0 0 0 7 2}$ \\
3 & Opioid_0 & 0.874445 & $\mathbf{0 . 0 0 0 0 0 8}$ & & 0.587783 \\
4 & Opioid_1 & 0.950398 & $\mathbf{0 . 0 0 0 0 7 2}$ & 0.587783 &
\end{tabular}

Bold values are significantly important statistical values $(p<0.05)$.

and neuronal release of the brain dopaminergic system, which could heal the abnormal cravings (Blum et al., 2000; Anselme and Robinson, 2013).

These results indicate the importance of cortico-subcortical loops in decision making when performing an IGT test. Mesolimbic dopamine is the main transmitter in striatum that is released to a larger extent in pathological gamblers than in healthy individuals (Linnet et al., 2011, 2012; Potenza, 2018). The impulsive, addictive, and compulsive behaviors have common characteristics (Brevers et al., 2014; Lorains et al., 2014).
Individuals with Reward Deficiency Syndrome (RDS) differ with their reactions in comparison with healthy people. It has been assumed that there is a relationship between psycho-motor ability and decision making. The working hypothesis is that people who suffer from RDS process decisions differently than healthy people. The postulated reason for this difference is based on the observation that the activity of the limbic loop (which is responsible for the processing of emotions) in individuals with the impaired RDS (Fotros et al., 2013).

In contrast, it is interesting that people addicted to gambling make less risky decisions compared to opioid-dependent individuals before the administration of methadone.

Four independent groups were compared in these studies:

- Gambling addicts,

- Opioid addicts treated with methadone substitution before administration of this drug,

- Opioid addict treated with substitution after administration of methadone,

- Healthy individuals.

The Iowa Gambling Test was performed only once. This procedure excludes the learning effect (Pasion et al., 2017; Almy et al., 2018). Previous results of our own research indicate that administration of a 
substitution drug in opioid dependent individuals improves decision making.

It has been observed that the substitution drug (methadone) reduces the level of risky behavior in opioid addicts (Gorzelańczyk et al., 2014). It is interesting to see whether the decision-making strategy before administration of the substitution drug is similar in opioid addicts to the strategy in those who are addicted to gambling and whether the decisionmaking strategy after administration of the drug is similar to healthy individuals, which has been stated in inter alia: (King et al., 2015; Gallimberti et al., 2016).

To summarize the overall discussion, it is important to mention that a common neurobiological mechanism for chemical and behavioral addictions is still postulated, however, clinical observations and research results show some differences between different types of addiction (Jiang et al., 2020).

The IGT performance strategy is for gamblers and opioid dependent individuals without a similar substitution drug administration. But it is important to mention that gamblers' strategy leads to an endpoint similar to that of opioid addicts without administration of the drug (opioid).

The gamblers have the potential to learn from mistakes, but for some reason, during the IGT processing time, they stop learning. The explanation may be the strong activation of the striatum in gamblers at the beginning of the test, which results in the control of subcortical structures and the lack of effective inhibition of the striatum by the cerebral cortex.

Perhaps playing is much more important than winning for gamblers, as for them the game is a trigger, and it is difficult to stop the process. This is perhaps a similar mechanism to the one in alcoholics, thus gaming for gamblers is the same as an alcoholic going on a drinking binge (Cavicchioli et al., 2018).

The above mentioned mechanisms observed in gamblers are similar to the pattern followed by alcohol or drug addicted individuals.

Presumably, just joining the game temporarily increases the cognitive performance of gamblers. The IGT cues are consistent with gambling addiction and they easily fall into a binge. This is why gamblers quickly deplete cognitive resources due to the type of stimuli-although their absolute resources are greater compared to those addicted to opioids.

In opioid addicts, decision making also depends on the type of substitution drug used for substitution treatment (Pirastu et al., 2006). It was found that methadone administration is associated with impairment in the decision making ability but during dosage increase the decision making appears to improve (Barahmand et al., 2016).

These results indicate that stimulation of the reward system in both gambling addicts and opioid addicts is similarly difficult, and administration of substitution medication does not significantly reduce the response time of the opioid addicts.

It is possible to observe a significant decrease of scores and response times after penalty during the fourth deck in gambling individuals during the IGT task performance. This is assumed to be the consequence of control taking by subcortical structures and clear evidence of a reward system deficit, which results in particular decisions being taken by the addicted participants of this study and is impossible to observe in healthy, non-addicted individuals.

According to the authors' knowledge, no data are available in the literature characteristics for addicted individuals to drop at the fourth trial of the IGT. This result requires confirmation and further research.

Original results can also indicate that stimulation of the reward system in both gambling addicts and opioid addicts is similarly difficult, and administration of substitution medication does not significantly reduce the response time of opioid addicts. It is possible that the reward system is more difficult to stimulate in addicts in comparison to healthy people.

There are some limitations regarding gender ratio among the participants between the groups tested. In our original research it was found that gambling addiction is much more common among male compared to female among prisoners. However, the behavioral strategy in performing the IGT test is quite specific for gambling addicts. Further research is necessary in terms of gender and education. Also, the female prisoner ratio is significantly lower than male poland (2020).

Interestingly, the administration of opioid substitution drugs-methadone improves the performance of the IGT test (reduces the level of risky behavior) in opioid addicted individuals. Even though an improvement is observed during the IGT test performance in opioid addicted individuals after methadone administration, compared to the level of performance reached by gamblers, this improvement did not reach the level of performance observed in healthy, non-addicted individuals.

It is interesting that the average response time from noticing the reward to pressing the button is greater in gamblers in comparison to the response time of healthy individuals. This result may indicate that the activation of the reward system in gamblers is more difficult in comparison with the participants from the control group.

The results of the presented studies show that, in opioid addicts treated with methadone in the substitution treatment program, a single dose of methadone affects the number of risk behaviors measured by the IGT test.

The results of the presented studies indicate that, in opioid addict individuals treated with methadone in the substitution treatment program, a single dose of methadone affects the level of risk behaviors measured by the IGT test. It is possible that the risk behavior in individuals addicted to opioids can differ from gambling addicted individuals, despite some assumptions regarding similarity of both. The level of risky behavior in both addictions was compared during this study, including time-response during tasks. It was observed on the basis of the whole IGT test that gambling addicted individuals take more risky decisions in comparison to healthy individuals from the control group but less risky decisions in comparison to opioid addicted individuals before administration of methadone and without any statistically significant difference after administration of methadone. Various research and clinical observations postulate that there are both some similarities and some differences between drug addiction and behavioral addiction symptoms (Kluwe-Schiavon et al., 
2019). Finding objective differences in behavior strategies can help to distinguish between substance-and gambling-addicts (Kriegler et al., 2019).

Addicted people more frequently display risky behavior. The analysis of respondents after the administration of methadone showed a statistically significantly decrease of the tendency to display risky behaviors. Results of studies (based on authors' experience and literature study) show that addicted people tend to display risky behaviors in subsequent attempts of the IGT test.

It is also important to consider individual differences in risktolerance, as these are crucial factors in taking risky decisions. Some dependency between obesity and various addictions (Yi et al., 2007; Rasmussen et al., 2010; Petry, 2012; Castren et al., 2015) was also found. Another meaningful factor is gender-based, as some studies show that men are more prone to addiction than women. Further studies in this area would be an advantage (Carneiro et al., 2019). Appropriate stimuli can affect decisions made for choosing the correct reward (Blanchard et al., 2015; Smith et al., 2016, 2017; Zentall, 2016).

The authors of this paper would like in the near future to investigate other pharmacological agents, such as inter alia: including serotonin reuptake inhibitors (SRIs), opioid antagonists, glutamatergic agents, and the antidopaminergic medication olanzapine, which gave (based on a literature study) promising results, as described in Chamberlain and Grant (2019).

It is also planned to differentiate the obtained results based on the gender of the tested individuals (Carneiro et al., 2019). There is a limitation regarding the level of education, resulting from the source of the acquired material. However, the behavioral strategy in performing the IGT test is quite specific for gambling addicts. Further research is necessary in terms of gender and education and should be expanded in further research plans.

\section{REFERENCES}

(2020). Poland-World Prison Brief. Available online at: https://www.prisonstudies. org/country/poland (accessed October 12, 2020).

Ahmadi, K., Javadinia, S. A., Saadat, S. H., Ramezani, M. A., and Sedghijalal, H. (2017). Itriangular relationship among risky sexual behavior, addiction, and aggression: a systematic review. Electron Phys. 9, 5129-5137. doi: $10.19082 / 5129$

Ahn, W.-Y., Ramesh, D., Moeller, F. G., and Vassileva, J. (2016b). Utility of machine-learning approaches to identify behavioral markers for substance use disorders: impulsivity dimensions as predictors of current cocaine dependence. Front. Psychiatry 7:34. doi: 10.3389/fpsyt.2016.00034

Ahn, W. Y., Dai, J., Vassileva, J., Busemeyer, J. R., and Stout, J. C. (2016a). "Computational modeling for addiction medicine: from cognitive models to clinical applications," in Progress in Brain Research, Vol. 224, eds H. Ekhtiari and M. P. Paulus (Elsevier), 53-65. doi: 10.1016/bs.pbr.2015.07.032

Almy, B., Kuskowski, M., Malone, S. M., Myers, E., and Luciana, M. (2018). A longitudinal analysis of adolescent decision-making with the Iowa gambling task. Dev. Psychol. 54:689. doi: 10.1037/dev0000460

American Psychiatric Association (2013). Diagnostic and Statistical Manual of Mental Disorders, 5th Edn. Arlington, VA: American Psychiatric Association.

\section{DATA AVAILABILITY STATEMENT}

The datasets used and analyzed during the current study will be made available by the corresponding author upon reasonable request.

\section{ETHICS STATEMENT}

The studies involving human participants were reviewed and approved by Bioethics Commission at Medical College in Bydgoszcz, Nicolaus Copernicus University in Torun, Poland was obtained (Consent no. KB/416/2008). The patients/participants provided their written informed consent to participate in this study.

\section{AUTHOR CONTRIBUTIONS}

EG: designed the study protocol, recruited participants, carried out research, and prepared the draft version of the paper. PW: carried out research and analyzed the results. MB: performed deep literature study, partially wrote the Future Works section and the Discussion. AK-S: prepared the final version of the manuscript, expanded the draft version, performed a very thorough literature study, proof-read the article, prepared the template, and partially wrote the Discussion and Future Works sections. EL: helped with the patients recruitment and carried out the study. All authors contributed to the article and approved the submitted version.

\section{FUNDING}

Program of the Polish Ministry of Health financed by Gambling Problems Funds contracted by the National Bureau for Drug Prevention-under the project: Carrying out research to increase knowledge in the field of addiction grant number $68 / \mathrm{H} / \mathrm{E} / 2015$ of 02.03.2015 and $6 / H / E / K / 2016$ of 04.01.2016.
Anselme, P., and Robinson, M. J. F. (2013). What motivates gambling behavior? Insight into dopamine's role. Front. Behav. Neurosci. 7:182. doi: 10.3389/fnbeh.2013.00182

Barahmand, U., Tavakolian, E., Khazaee, A., and Mohammadi, K. (2016). Hot and cold executive functions in pure opioid users undergoing methadone maintenance treatment: effects of methadone dose, treatment duration, and time between last methadone administration and testing. Nigerian J. Clin. Pract. 19, 603-610. doi: 10.4103/1119-3077.188695

Bechara, A., Damasio, A. R., Damasio, H., and Anderson, S. W. (1994). Insensitivity to future consequences following damage to human prefrontal cortex. Cognition 50, 7-15. doi: 10.1016/0010-0277(94)90018-3

Bechara, A., and Damasio, H. (2002). Decision-making and addiction (Part I): impaired activation of somatic states in substance dependent individuals when pondering decisions with negative future consequences. Neuropsychologia 40, 1675-1689. doi: 10.1016/S0028-3932(02)00015-5

Bechara, A., Dolan, S., and Hindes, A. (2002). Decision-making and addiction (Part II): myopia for the future or hypersensitivity to reward? Neuropsychologia 40, 1690-1705. doi: 10.1016/S0028-3932(02)00016-7

Blanchard, T. C., Hayden, B. Y., and Bromberg-Martin, E. S. (2015). Orbitofrontal cortex uses distinct codes for different choice attributes in decisions motivated by curiosity. Neuron 85, 602-614. doi: 10.1016/j.neuron.2014.12.050 
Blum, K., Braverman, E. R., Holder, J. M., Lubar, J. F., Monastra, V. J., Miller, D., et al. (2000). The reward deficiency syndrome: a biogenetic model for the diagnosis and treatment of impulsive, addictive and compulsive behaviors. $J$. Psychoact. Drugs 32(Suppl. 1), 1-112. doi: 10.1080/02791072.2000.10736099

Brevers, D., Bechara, A., Cleeremans, A., and Noel, X. (2013). Iowa gambling task (IGT): twenty years after-gambling disorder and IGT. Front. Psychol. 4:665. doi: 10.3389/fpsyg.2013.00665

Brevers, D., Koritzky, G., Bechara, A., and Noël, X. (2014). Cognitive processes underlying impaired decision-making under uncertainty in gambling disorder. Addict. Behav. 39, 1533-1536. doi: 10.1016/j.addbeh.2014.06.004

Brevers, D., Noël, X., He, Q., Melrose, J. A., and Bechara, A. (2016). Increased ventral-striatal activity during monetary decision making is a marker of problem poker gambling severity. Addict. Biol. 21, 688-699. doi: $10.1111 / \mathrm{adb} .12239$

Briére, M., Tocanier, L., Allain, P., Le Gal, D., Allet, G., Gorwood, P., et al. (2019). Decision-making measured by the Iowa gambling task in patients with alcohol use disorders choosing harm reduction versus relapse prevention program. Eur. Addict. Res. 25, 182-190. doi: 10.1159/000499709

Carneiro, E., Tavares, H., Sanches, M., Pinsky, I., Caetano, R., Zaleski, M., et al. (2019). Gender diferences in gambling exposure and at-risk gambling behavior. J. Gambl. Stud. 35, 1-13. doi: 10.1007/s10899-019-09884-7

Castren, S., Salonen, A. H., Alho, H., Lahti, T., and Simojoki, K. (2015). Past-year gambling behaviour among patients receiving opioid substitution treatment. Subst. Abuse Treat. Prevent. Policy 10:4. doi: 10.1186/1747-597X-10-4

Cavicchioli, M., Vassena, G., Movalli, M., and Maffei, C. (2018). Addictive behaviors in alcohol use disorder: dysregulation of reward processing systems and maladaptive coping strategies. J. Addict. Dis. 37, 173-184. doi: 10.1080/10550887.2019.1643211

Chamberlain, S. R., and Grant, J. E. (2019). Efficacy of pharmacological interventions in targeting decision-making impairments across substance and behavioral addictions. Neuropsychol. Rev. 29, 93-102. doi: 10.1007/s11065-019-09400-Z

Chen, M., Sun, Y., Lu, L., and Shi, J. (2017). "Similarities and differences in neurobiology," in Substance and Non-substance Addiction, eds X. Zhang, J. Shi and R. Tao (Singapore: Springer), 45-58. doi: 10.1007/978-981-10-5562-1_3

Coppola, M., Mondola, R., et al. (2017). Opioid receptor antagonists in the treatment of pathological gambling. J. Opioid Manage. 13, 205-206. doi: 10.5055/jom.2017.0388

Dixon, M. L., Thiruchselvam, R., Todd, R., and Christoff, K. (2017). Emotion and the prefrontal cortex: an integrative review. Psychol. Bull. 143:1033. doi: $10.1037 /$ bul0000096

Engel, A., and Caceda, R. (2015). Can decision making research provide a better understanding of chemical and behavioral addictions? Curr. Drug Abuse Rev. 8, 75-85. doi: 10.2174/1874473708666150916113131

Epstein, J., and Silbersweig, D. (2016). The neuropsychiatric spectrum of motivational disorders. Focus 14, 499-509. doi: 10.1176/appi.focus.140401

Fineberg, N. A., Potenza, M. N., Chamberlain, S. R., Berlin, H. A., Menzies, L., Bechara, A., et al. (2010). Probing compulsive and impulsive behaviors, from animal models to endophenotypes: a narrative review. Neuropsychopharmacology 35, 591-604. doi: 10.1038/npp.2009.185

Fotros, A., Casey, K. F., Larcher, K., Verhaeghe, J. A., Cox, S. M., Gravel, P., et al. (2013). Cocaine cue-induced dopamine release in amygdala and hippocampus: a high-resolution pet [18 f] fallypride study in cocaine dependent participants. Neuropsychopharmacology 38, 1780-1788. doi: 10.1038/npp.2013.77

Gallimberti, L., Buja, A., Chindamo, S., Terraneo, A., Marini, E., Perez, L. J. G., et al. (2016). Experience with gambling in late childhood and early adolescence: implications for substance experimentation behavior. J. Dev. Behav. Pediatr. 37, 148-156. doi: 10.1097/DBP.0000000000000252

Gilman, J. M., Smith, A. R., Bjork, J. M., Ramchandani, V. A., Momenan, R., and Hommer, D. W. (2015). Cumulative gains enhance striatal response to reward opportunities in alcohol-dependent patients. Addict. Biol. 20, 580-593. doi: $10.1111 / \mathrm{adb} .12147$

Gorzelańczyk, E. J., Fareed, A., Walecki, P., Feit, J., and Kunc, M. (2014). Risk behavior in opioid-dependent individuals after the administration of a therapeutic dose of methadone. Am. J. Addict. 23, 608-612. doi: 10.1111/j.1521-0391.2014.12154.x

Gorzelańczyk, E. J., Walecki, P., Feit, J., Kunc, M., and Fareed, A. (2016). Improvement of saccadic functions after dosing with methadone in opioid addicted individuals. J. Addict. Dis. 35, 52-57. doi: 10.1080/10550887.2016.1107289

Hilber, P., Cendelin, J., Le Gall, A., Machado, M.-L., Tuma, J., and Besnard, S. (2019). Cooperation of the vestibular and cerebellar networks in anxiety disorders and depression. Prog. Neuro Psychopharmacol. Biol. Psychiatry 89, 310-321. doi: 10.1016/j.pnpbp.2018.10.004

Hu, W.-L., Tsai, M.-C., Kuo, C.-E., Liu, C.-T., Wu, S.-Y., Wu, T.-C., et al. (2019). Adjuvant laser meridian massage in men with opioid use disorder on methadone maintenance treatment: protocol for a case-controlled study. Medicine 98:e17319. doi: 10.1097/MD.0000000000017319

Jiang, C., Li, C., Zhou, H., and Zhou, Z. (2020). Las personas con trastorno de juego en internet tienen deficiencias neurocognitivas y disfunciones sociocognitivas similares a los pacientes con dependencia de la metanfetamina/individuals with internet gaming disorder have similar neurocognitive impairments and social cognitive dysfunctions as methamphetamine-dependent patients. Adicciones. doi: 10.20882/adicciones. 1342

Kelty, E., Hulse, G., Joyce, D., and Preen, D. B. (2020). Impact of pharmacological treatments for opioid use disorder on mortality. CNS Drugs. 34, 629-642. doi: 10.1007/s40263-020-00719-3

Khoury, J. M., Couto, L. F. S. C., Santos, D. D. A., Drumond, J. P. S. Malloy-Diniz, L., Albuquerque, M. R., et al. (2019). Bad choices make good stories: the impaired decision-making process and skin conductance response in subjects with smartphone addiction. Front. Psychiatry 10:73. doi: 10.3389/fpsyt.2019.00397

Kim, K. M., Choi, S.-W., Kim, D., Lee, J., and Kim, J. W. (2019). Associations among the opioid receptor gene (OPRM1) A118G polymorphism, psychiatric symptoms, and quantitative EEG in Korean males with gambling disorder: a pilot study. J. Behav. Addict. 8, 463-470. doi: 10.1556/2006.8.2019.41

King, D. L., Gainsbury, S. M., Delfabbro, P. H., Hing, N., and Abarbanel, B. (2015). Distinguishing between gaming and gambling activities in addiction research. J. Behav. Addict. 4, 215-220. doi: 10.1556/2006.4.2015.045

Kluwe-Schiavon, B., Viola, T., Sanvicente-Vieira, B., Lumertz, F., Salum, G. A., Grassi-Oliveira, R., et al. (2019). Substance related disorders are associated with impaired valuation of delayed gratification and feedback processing: a multilevel meta-analysis and meta-regression. Neurosci. Biobehav. Rev. 108, 295-307. doi: 10.1016/j.neubiorev.2019.11.016

Kovács, I., Richman, M. J., Janka, Z., Maraz, A., and Andó, B. (2017). Decision making measured by the Iowa gambling task in alcohol use disorder and gambling disorder: a systematic review and meta-analysis. Drug Alcohol Depend. 181, 152-161. doi: 10.1016/j.drugalcdep.2017.09.023

Kriegler, J., Wegener, S., Richter, F., Scherbaum, N., Brand, M., and Wegmann, E. (2019). Decision making of individuals with heroin addiction receiving opioid maintenance treatment compared to early abstinent users. Drug Alcohol Depend. 205:107593. doi: 10.1016/j.drugalcdep.2019.107593

Leeman, R. F., and Potenza, M. N. (2012). Similarities and differences between pathological gambling and substance use disorders: a focus on impulsivity and compulsivity. Psychopharmacology 219, 469-490. doi: 10.1007/s00213-011-2550-7

Lin, C.-H., Wang, C.-C., Sun, J.-H., Ko, C.-H., and Chiu, Y.-C. (2019). Is the clinical version of the Iowa gambling task relevant for assessing choice behavior in cases of internet addiction? Front. Psychiatry 10:232. doi: $10.3389 /$ fpsyt.2019.00232

Linnet, J., Møller, A., Peterson, E., Gjedde, A., and Doudet, D. (2011). Dopamine release in ventral striatum during Iowa gambling task performance is associated with increased excitement levels in pathological gambling. Addiction 106, 383-390. doi: 10.1111/j.1360-0443.2010.03126.x

Linnet, J., Mouridsen, K., Peterson, E., Møller, A., Doudet, D. J., and Gjedde, A. (2012). Striatal dopamine release codes uncertainty in pathological gambling. Psychiatry Res. Neuroimaging 204, 55-60. doi: 10.1016/j.pscychresns.2012.04.012

Lorains, F. K., Dowling, N. A., Enticott, P. G., Bradshaw, J. L., Trueblood, J. S. and Stout, J. C. (2014). Strategic and non-strategic problem gamblers differ on decision-making under risk and ambiguity. Addiction 109, 1128-1137. doi: 10.1111/add.12494

Majuri, J., Joutsa, J., Johansson, J., Voon, V., Alakurtti, K., Parkkola, R., et al. (2017). Dopamine and opioid neurotransmission in behavioral addictions: a comparative pet study in pathological gambling and binge eating. Neuropsychopharmacology 42, 1169-1177. doi: 10.1038/npp.2016.265 
Mallorquí-Bagué, N., Fagundo, A. B., Jimenez-Murcia, S., De la Torre, R., Baños, R. M., Botella, C., et al. (2016). Decision making impairment: a shared vulnerability in obesity, gambling disorder and substance use disorders? PLoS ONE 11:e0163901. doi: 10.1371/journal.pone.0163901

Mueller, S. T., and Piper, B. J. (2014). The psychology experiment building language (PEBL) and PEBL test battery. J. Neurosci. Methods 222, 250-259. doi: 10.1016/j.jneumeth.2013.10.024

Nautiyal, K. M., Okuda, M., Hen, R., and Blanco, C. (2017). Gambling disorder: an integrative review of animal and human studies. Ann. N. Y. Acad. Sci. 1394:106. doi: $10.1111 /$ nyas. 13356

Pasion, R., Gonçalves, A. R., Fernandes, C., Ferreira-Santos, F., Barbosa, F., and Marques-Teixeira, J. (2017). Meta-analytic evidence for a reversal learning effect on the Iowa gambling task in older adults. Front. Psychol. 8:1785. doi: 10.3389/fpsyg.2017.01785

Petry, N. M. (2012). Discounting of probabilistic rewards is associated with gambling abstinence in treatment-seeking pathological gamblers. J. Abnormal Psychol. 121, 151-159. doi: 10.1037/a0024782

Pirastu, R., Fais, R., Messina, M., Bini, V., Spiga, S., Falconieri, D., et al. (2006). Impaired decision-making in opiate-dependent subjects: effect of pharmacological therapies. Drug Alcohol Depend. 83, 163-168. doi: $10.1016 /$ j.drugalcdep.2005.11.008

Potenza, M. N. (2018). Searching for replicable dopamine-related findings in gambling disorder. Biol. Psychiatry 83:984. doi: 10.1016/j.biopsych.2018.04.011

Rasmussen, E. B., Lawyer, S. R., and Reilly, W. (2010). Percent body fat is related to delay and probability discounting for food in humans. Behav. Process. 83, 23-30. doi: 10.1016/j.beproc.2009.09.001

Schwaninger, P. V., Mueller, S. E., Dittmann, R., Poespodihardjo, R., Vogel, M., Wiesbeck, G. A., et al. (2017). Patients with non-substance-related disorders report a similar profile of childhood trauma experiences compared to heroindependent patients. Am. J. Addict. 26, 215-220. doi: 10.1111/ajad.12512

Smith, A. P., Bailey, A. R., Chow, J. J., Beckmann, J. S., and Zentall, T. R. (2016). Suboptimal choice in pigeons: Stimulus value predicts choice over frequencies. PLoS ONE 11:e0159336. doi: 10.1371/journal.pone.0159336

Smith, A. P., Beckmann, J. S., and Zentall, T. R. (2017). Gambling-like behavior in pigeons: "jackpot” signals promote maladaptive risky choice. Sci. Rep. 7:6625. doi: 10.1038/s41598-017-06641-x

Tanabe, J., Thompson, L., Claus, E., Dalwani, M., Hutchison, K., and Banich, M. T. (2007). Prefrontal cortex activity is reduced in gambling and nongambling substance users during decision-making. human brain mapping. Hum. Brain Mapp. 28, 591-604. doi: 10.1002/hbm.20344

Tarnowska, E., Wicher, A., Sęk, A., and Gorzelańczyk, E. J. (2018). The influence of a single therapeutic dose of methadone on selected auditory functions in patients addicted to opioids and undergoing substitution therapy-a preliminary study. Arch. Acoust. 43, 137-146. doi: 10.24425/118089

Trotzke, P., Starcke, K., Müller, A., and Brand, M. (2019). Cue-induced craving and symptoms of online-buying-shopping disorder interfere with performance on the Iowa gambling task modified with online-shopping cues. Addict. Behav. 96, 82-88. doi: 10.1016/j.addbeh.2019.04.008

Upton, D. J., Kerestes, R., and Stout, J. C. (2012). Comparing the Iowa and Soochow gambling tasks in opiate users. Front. Neurosci. 6:34. doi: $10.3389 /$ fnins.2012.00034

Vasconcelos, M., Monteiro, T., and Kacelnik, A. (2015). Irrational choice and the value of information. Sci. Rep. 5:13874. doi: 10.1038/srep13874

Vegni, N., Melchiori, F. M., D’Ardia, C., Prestano, C., Canu, M., Piergiovanni, G., et al. (2019). Gambling behavior and risk factors in preadolescent students: a cross sectional study. Front. Psychol. 10:1287. doi: 10.3389/fpsyg.2019.01287

Victorri-Vigneau, C., Spiers, A., Caillet, P., Bruneau, M., Challet-Bouju, G., GrallBronnec, M., et al. (2018). Opioid antagonists for pharmacological treatment of gambling disorder: are they relevant? Curr. Neuropharmacol. 16, 1418-1432. doi: 10.2174/1570159X15666170718144058

Volkow, N. D., Woodcock, J., Compton, W. M., Throckmorton, D. C., Skolnick, P., Hertz, S., et al. (2018). Medication development in opioid addiction: meaningful clinical end points. Sci. Transl. Med. 10, 1-2. doi: 10.1126/scitranslmed.aan2595

Weinstein, A., Livny, A., and Weizman, A. (2017). New developments in brain research of internet and gaming disorder. Neurosci. Biobehav. Rev. 75, 314-330. doi: 10.1016/j.neubiorev.2017.01.040

Yau, M. Y. H., and Potenza, M. N. (2015). Gambling disorder and other behavioral addictions: recognition and treatment. Harvard Rev. Psychiatry 23:134. doi: 10.1097/HRP.0000000000000051

Yi, R., Chase, W. D., and Bickel, W. K. (2007). Probability discounting among cigarette smokers and nonsmokers: molecular analysis discerns group differences. Behav. Pharmacol. 18, 633-639. doi: 10.1097/FBP.0b013e3282effbd3

Zeng, H., Su, D., Jiang, X., Zhu, L., and Ye, H. (2016). The similarities and differences in impulsivity and cognitive ability among ketamine, methadone, and non-drug users. Psychiatry Res. 243, 109-114. doi: 10.1016/j.psychres.2016.04.095

Zentall, T. R. (2016). Resolving the paradox of suboptimal choice. J. Exp. Psychol. Anim. Learn. Cogn. 42, 1-14. doi: 10.1037/xan0000085

Conflict of Interest: The authors declare that the research was conducted in the absence of any commercial or financial relationships that could be construed as a potential conflict of interest.

Copyright (C) 2021 Gorzelańczyk, Walecki, Błaszczyszyn, Laskowska and KawalaSterniuk. This is an open-access article distributed under the terms of the Creative Commons Attribution License (CC BY). The use, distribution or reproduction in other forums is permitted, provided the original author(s) and the copyright owner(s) are credited and that the original publication in this journal is cited, in accordance with accepted academic practice. No use, distribution or reproduction is permitted which does not comply with these terms. 